\title{
Research supervision: Perceptions of postgraduate nursing students at a higher education institution in KwaZulu-Natal, South Africa
}

\author{
C Muraraneza, ${ }^{1} \mathrm{MN}$; F Mtshali, ${ }^{1} \mathrm{PhD}$; S Z Mthembu, ${ }^{2} \mathrm{PhD}$ \\ ${ }^{1}$ Department of Nursing, School of Nursing and Public Health, University of KwaZulu-Natal, Durban, South Africa \\ ${ }^{2}$ KwaZulu-Natal College of Nursing, Department of Health, Pietermaritzburg, South Africa
}

Corresponding author: SZ Mthembu (sindizama@gmail.com)

Background. Scientific advancement, particularly in the area of information communication technology (ICT), challenges the mode of knowledge advancement at universities. Such challenges are especially evident in the area of postgraduate (PG) research supervision, particularly in the light of the changing students' demography, whereby there is a radical shift from full-time campus-based students to part-time students. This challenge is compounded by many countries not considering research competency as a requirement for PG supervision - the result of static and outdated curricula. Objective. To explore the perceptions of PG nursing students with regard to the research supervision process.

Methods. A quantitative research study was conducted at the University of KwaZulu-Natal (UKZN), Durban, South Africa using non-convenience sampling. The PG Research Experience Survey questionnaire was adapted for the current study. Ethical clearance was obtained from UKZN's Ethics Committee. The population consisted of the PG coursework Master's nursing students who were registered for the research project module during 2012. A total of 56 students participated, with a response rate of 70\%. Data were analysed using the Statistical Package for the Social Sciences 19 (SPSS 19) (IBM Corp., USA). Results. The findings revealed that more than half of the respondents $(66.2 \% ; n=37)$ rated the level of support from research supervisors as moderate on a scale of low to high. The period of research supervision, mode of attendance and status within the university were identified as factors influencing the perceptions of support from research supervisors.

Conclusion. This study recommends that, to improve the quality of research supervision, there is a need to include a research supervision module in the curriculum of nurse educators and to adopt online research supervision, underpinned by the extensive use of ICT to accommodate both part-time and full-time PG students.

Afr J Health Professions Educ 2016;8(2):135-139. DOI:10.7196/AJHPE.2016.v8i2.294

One of the realities of contemporary society is the rapid emergence and growth of a knowledge-based economy owing to the use of information communication technology (ICT). Undoubtedly, universities are major roleplayers in knowledge generation. ${ }^{[1]}$ This function of universities underpins the development of postgraduate (PG) students as competent knowledge generators and scholars. However, the ICT revolution is challenging many universities to transform their traditional approach towards research supervision into knowledge production. ${ }^{[2]}$ The research supervision process is expected to transform research candidates into knowledge producers and managers, with research supervisors playing an informed, supportive role in students' research journeys.

The dynamics and complexities of the current environment demand a change from conventional research supervision processes. Before 2000, PG students were full-time resident students, thus making it easy for supervisors to have close, personal and individualised contact with them. ${ }^{[2]}$ The current environment, however, demands a change, as the old model is unsuitable for students and supervisors, who are now both more mobile. Furthermore, an increasing number of PG students work full time, making the traditional model of supervision inappropriate and obsolete. ${ }^{[3]}$

Trudgett ${ }^{[4]}$ acknowledges that high-quality supervision is strongly associated with the capacity of academic staff. PG research supervision requires sound knowledge in terms of research methodology, and facilitation and management skills from research supervisors. In developed countries, research supervision is one of the competencies of nursing education programmes. However, this is not the case in countries where the curriculum of health professionals appears static and outdated, ${ }^{[5]}$ as in South Africa (SA). Until 2012, the SA Nursing Council (SANC) did not include research supervision in the training curriculum of nurse educators. This has been identified as a weakness, given that a nursing qualification requires a research project at both diploma and degree level. ${ }^{[6]}$ Nurse educators have been learning to supervise research through trial and error, and/or by informal training, such as workshops.

This gap in the training of nurse educators may result in low in- and output in the research supervision process. This, in turn, decreases the nature of support, guidance and facilitation provided to PG nursing students and consequently the reduced throughput of these students. Between 2000 and 2006, at the College of Health Sciences, University of KwaZulu-Natal (UKZN), Durban, SA the average drop-out rate at Master's level for thesisbased coursework was $56 \%$, while the completion rate for Master's and Doctoral students averaged $11 \%$ and $10 \%$, respectively. ${ }^{[7]}$ Furthermore, studies reported a rapidly increasing number of PG students, most of whom were underprepared with regard to research. ${ }^{[8-10]}$

With the foregoing in mind, the following research questions directed this study:

- What perceptions do PG nursing students have of research supervisors?

- Which factors influence the manner in which PG nursing students perceive the expertise of their research supervisors?

A coursework Master's degree is one of the PG education health professionals programmes aimed at increasing professionalism in the discipline. Research constitutes $50 \%$ of the credits of the degree; ${ }^{[11]}$ therefore, information on research supervision processes from PG nursing students would be useful in improving and enhancing the quality of the supervision. This could have a positive effect, resulting in an increase in the output of PG students. 


\section{Methods}

This study comprised a quantitative and descriptive research method using non-convenience sampling, and was done at a selected university in KwaZulu-Natal, a province of SA.

The PG Research Experience Survey (PRES) questionnaire of the Higher Education Academy in the $\mathrm{UK}^{[12]}$ was adapted for this study. To assess research processes, 10 items were added to the instrument. The reliability of the research instrument was checked by a pilot study of five coursework Master's nursing students from the school where this study took place. These students did not participate in the final study. Cronbach's $\alpha$ test was performed $(\alpha=0.91)$, indicating strong reliability of the instrument. The same results were obtained in a previous study done by Abdullah and Evans, ${ }^{[13]}$ without the 10 additional items. Ethical clearance (HSS/0363/012M) was obtained from the University's Research Ethics Committee.

The questionnaire and informed consent forms were sent to all the coursework Master's nursing students who had registered for the research project module during the 2012 academic year. The questionnaire was sent via the students' e-mail addresses with the assistance of the PG administrative office. In addition, hard copies were also given to the respondents who preferred this means of participation. Eighty questionnaires were distributed and 56 students participated, i.e. a response rate of $70 \%$.

The data were analysed using the Statistical Package for the Social Sciences 19 (SPSS 19) (IBM Corp., USA). The tool comprised a 4-point Likert scale varying from 1 (strongly disagree) to 4 (strongly agree). Descriptive statistics such as frequencies, percentages, means and standard deviations were used to describe the quantitative data. Inferential statistical methods were used to test the relationships among variables to identify factors that influence how PG students perceive their research supervisors. A $p$-value $\leq 0.05$ was considered to be significant.

\section{Results}

\section{Sociodemographic characteristics of respondents}

The mean age of the respondents was 43.02 years. The minimum period of research supervision was 5 months, while the maximum was 36 months (3 years), with a mean of 14 months. The largest proportion of the total sample consisted of females $(83.9 \%$; $n=47)$, with males representing only $16.1 \%(n=9)$. The majority of respondents $(80.4 \% ; n=45)$ were part-time students, while $19.6 \%(n=11)$ were full-time students. There were $46(82 \%)$ local and $10(18 \%)$ international students. Less than half of the sample (46.4\%; $n=26)$ had a Bachelor of Nursing degree, while $10 \%(n=5)$ had a Bachelor of Nursing: Advanced Practice (BNAP) degree, and 44.6\% $(n=25)$ had an Honours degree in nursing. The sociodemographic characteristics of the sample are given in Table 1.

\section{Research supervisor skills}

One of the areas explored in this study is the students' perception of their supervisors' skills and knowledge of the subject area. More than half of the respondents $(60.7 \% ; n=34)$ strongly agreed that their supervisors had skills and subject knowledge to adequately supervise them. About $66 \%$ $(n=37)$ strongly agreed that they were guided with regard to the nature of the project expected at Master's level. However, less than half of the respondents (44.6\%; $n=25)$ moderately agreed that their supervisors made an effort to understand them, while $41.1 \%(n=23)$ strongly agreed with the statement.

\begin{tabular}{lll} 
Table 1. Sociodemographic characteristics of the sample & \\
\hline Sociodemographic variables & Attributes & $\boldsymbol{n}(\%)$ \\
\hline Gender & Female & $47(83.9)$ \\
& Male & $9(16.1)$ \\
Marital status & Single & $7(12.5)$ \\
& Married & $39(69.6)$ \\
& Divorced & $9(16.1)$ \\
Mode of attendance & Widow & $1(1.8)$ \\
& Full time & $11(19.6)$ \\
Status within university & Part time & $45(80.4)$ \\
& National & $46(82.0)$ \\
Previous academic & International & $10(18.0)$ \\
qualification & Bachelor's degree & $26(46.4)$ \\
& Bachelor of Nursing & $5(10.0)$ \\
& (Advanced Practice) & \\
Current nursing specialisation & Honours & $25(44.6)$ \\
& Nursing management & $12(21.4)$ \\
& Nursing education & $10(17.9)$ \\
& Community health & $13(23.2)$ \\
& Mental health & $6(10.7)$ \\
& Midwifery & $7(12.5)$ \\
& Critical care and trauma & $8(14.3)$ \\
& &
\end{tabular}

\section{Conceptualisation of research}

The conceptual phase is the first phase of the research process that refers to the developing and refining of abstract ideas. ${ }^{[14]}$ The perceptions of PG students in the conceptual phases were also described. Results of these descriptions showed that $51.8 \%(n=29)$ of the respondents strongly agreed, while $33.9 \%$ $(n=19)$ moderately agreed that they were given good guidance in selecting and refining their research topic. Only $37.5 \%(n=21)$ strongly agreed that they had been given guidance in the formulation and refinement of the purpose and objectives of the study, whereas $53.5 \%(n=30)$ moderately agreed. With regard to the theoretical or conceptual framework, respondents reported quite a low level of support from their supervisors. Only $30.3 \%(n=17)$ strongly agreed that they had been guided in relation to the choice of the theoretical or conceptual framework appropriate to their topic of study, while $39.3 \%(n=22)$ moderately agreed. More than a quarter of the respondents $(28.6 \% ; n=16)$ moderately disagreed that they received sufficient support in the choice of the theoretical or conceptual framework. The level of support received in terms of the literature review was higher compared with that received for the theoretical or conceptual framework. A quarter of the respondents $(25 \% ; n=14)$ strongly agreed, while $55.3 \%(n=31)$ moderately agreed that they had been guided by their research supervisors regarding the literature review component of their projects. Less than half of the respondents $(46.6 \%$; $n=25)$ strongly agreed, while $41.1 \%(n=23)$ moderately agreed that they had been given good guidance in terms of their research methodology, as depicted in Table 2.

\section{Nature of support from research supervisors}

PG students' perceptions of assistance from their research supervisors during data collection, data analysis, and report writing were explored. The findings of this study revealed that $62.5 \%(n=35)$ of respondents were 
Table 2. Students' perceptions of research supervisor(s)

\begin{tabular}{|c|c|c|c|c|c|}
\hline Students' perceptions & $\begin{array}{l}\text { SDI, } \\
n(\%)\end{array}$ & $\begin{array}{l}\text { MD, } \\
n(\%)\end{array}$ & $\begin{array}{l}\text { MA, } \\
n(\%)\end{array}$ & $\begin{array}{l}\text { SA, } \\
n(\%)\end{array}$ & Mean (SD) \\
\hline My supervisor(s) have the skills and subject knowledge to adequately support my research project & $2(3.6)$ & $2(3.6)$ & $32(18)$ & $34(60.7)$ & $3.50(0.73)$ \\
\hline $\begin{array}{l}\text { My supervisor(s) give me guidance about the nature of the research project and the standards } \\
\text { expected at Master's level }\end{array}$ & $1(1.8)$ & $4(7.2)$ & $14(25)$ & $37(66)$ & $3.55(0.71)$ \\
\hline $\begin{array}{l}\text { My supervisor(s) give me guidance about the time frame so that the dissertation may be } \\
\text { submitted on time }\end{array}$ & $3(5.4)$ & $3(5.4)$ & $19(33.9)$ & $31(55.3)$ & $3.39(0.82)$ \\
\hline My supervisor(s) make a real effort to understand any difficulties I face & $2(3.6)$ & $6(10.7)$ & $25(44.6)$ & $23(41.1)$ & $3.23(0.78)$ \\
\hline I have been given good guidance in topic selection and refinement by my supervisor(s) & - & $8(14.3)$ & $19(33.9)$ & $29(51.8)$ & $3.37(0.72)$ \\
\hline $\begin{array}{l}\text { I have been given guidance in formulation and refinement of purpose and objectives of the study } \\
\text { by my supervisor(s) }\end{array}$ & $1(1.8)$ & $4(7.2)$ & $30(53.5)$ & $21(37.5)$ & $3.28(0.67)$ \\
\hline My supervisor(s) guided me on the choice of the theoretical framework most appropriate to the study & $1(1.8)$ & $16(28.6)$ & $22(39.3)$ & $17(30.3)$ & $2.98(0.82)$ \\
\hline My supervisor(s) provide helpful feedback on my progress & - & $2(3.6)$ & $19(33.9)$ & $35(62.5)$ & $3.59(0.56)$ \\
\hline My supervisor(s) give me feedback in reasonable time & $1(1.8)$ & $15(26.8)$ & $21(37.5)$ & $19(33.9)$ & $3.03(0.83)$ \\
\hline I have received good guidance in my literature search from my supervisor(s) & $2(3.6)$ & $9(16.1)$ & $31(55.3)$ & $14(25.0)$ & $3.02(0.75)$ \\
\hline I have received good guidance on the methodology of my project from my supervisor(s) & $1(1.8)$ & $7(12.5)$ & $23(41.1)$ & $25(46.6)$ & $3.27(0.75)$ \\
\hline I have received good guidance from my supervisor(s) during data collection & $3(8.6)$ & $10(28.6)$ & $14(40.0)$ & $8(22.8)$ & $2.77(0.91)$ \\
\hline I have received good guidance from my supervisor(s) during data analysis & $1(3.3)$ & $11(36.7)$ & $13(43.3)$ & $5(16.7)$ & $2.73(0.78)$ \\
\hline I have received good guidance from my supervisor(s) during report writing & $1(3.6)$ & $8(28.6)$ & $12(42.8)$ & $7(25.0)$ & $2.89(0.83)$ \\
\hline The relationship between the supervisor(s) and me has been purely professional & - & $6(10.7)$ & $12(21.4)$ & $38(67.9)$ & $3.59(0.78)$ \\
\hline My supervisor(s) gave feedback that did not make me feel like she is attacking me as a person & $2(3.6)$ & $2(3.6)$ & $12(21.4)$ & $40(71.4)$ & $3.61(0.73)$ \\
\hline Overall mean of perceptions of research supervisor(s) & - & - & - & - & 3.23 \\
\hline
\end{tabular}

busy with the data collection phase at the time of the study. Of these, $22.8 \%(n=8)$ strongly agreed that they had received good guidance from their research supervisors with regard to data collection, $40 \%(n=14)$ moderately agreed, whereas $28.6 \%(n=10)$ moderately disagreed. Among the respondents, $53.6 \%(n=30)$ had reached the stage of data analysis. Of these, $16.7 \%$ $(n=5)$ strongly agreed that they had received good guidance from their research supervisors at this stage, $43.3 \%(n=13)$ moderately agreed, whereas $36.7 \%(n=11)$ moderately disagreed. Only $50 \%$ ( $n=28)$ were eligible to respond to the statement with regard to report writing. Of these, $25 \%(n=7)$ strongly agreed that they had received good guidance, while $42.8 \%$ ( $n=12)$ moderately agreed, and $28.6 \%(n=8)$ moderately disagreed.

\section{Nature of feedback}

Students' perceptions of the feedback provided and their relationship with research supervisors were explored. More than half of the respondents $(62.5 \% ; n=35)$ strongly agreed, while $33.9 \%$ $(n=19)$ moderately agreed that their research supervisors had provided helpful feedback on their progress. However, only $33.9 \%(n=19)$ strongly agreed that they were receiving feedback within a reasonable time period, while $37.5 \%$ $(n=21)$ moderately agreed. The majority of the respondents $(67.9 \% ; n=38)$ strongly agreed that they enjoyed a professional relationship with their research supervisors, $21.4 \%(n=12)$ moderately agreed, and $10.7 \%(n=6)$ moderately disagreed. Among the respondents, $71.4 \%(n=40)$ strongly agreed and $21.4 \%(n=12)$ moderately agreed that they had not felt subject to harsh criticism by their research supervisors while they were receiving feedback.

All scores of students' perceptions of their research supervisors were combined to describe the overall perception of the levels of support (Table 3). The majority of the respondents (66.1\%;

Table 3. Levels of support received from research supervisor(s)

\begin{tabular}{ll}
\hline Levels of support & $\boldsymbol{n}(\%)$ \\
\hline Low & $1(1.8)$ \\
Moderate & $37(66.1)$ \\
High & $18(32.1)$ \\
Total & $56(100.0)$
\end{tabular}

$n=37$ ) perceived a moderate level of support from their research supervisors, $32.1 \%(n=18)$ a high level of support, and only $1.8 \%(n=1)$ a low level of support. Furthermore, the overall mean perceptions of research supervisors' support was 3.23 out of 4 , i.e. $80.7 \%$ indicating perception of a high level of support.

\section{Discussion}

\section{Sociodemographic characteristics of respondents}

The findings of this study indicate that the respondents were predominantly female (83.9\%). This confirms the findings of other studies, where the nursing profession has been portrayed as a predominantly female profession since its foundation. ${ }^{[15]}$ Adult PG students face many challenges, such as family commitments, work commitments and financial burdens, which they have to overcome. These challenges may affect their academic achievement. ${ }^{[16]}$ The challenges are much greater if they are part-time students, as they have to manage their time and effort with regard to other commitments, including their jobs and families. The majority (55.3\%) of respondents spent $>10$ months under supervision - the time expected 
to complete the research project for both part-time and full-time PG students. Students are required to register and pay for each year of their research project. Moreover, the university loses funding from the government if students do not graduate within the expected time frame, as stipulated in the new funding framework for public higher education institutions (HEIs) in SA. ${ }^{[17]}$ In light of these, delayed throughput constitutes a waste of resources for both students and institutions. This places an extra burden on research supervisors, who have to supervise more students than expected - with decreased funding. Therefore, scholarship development is compromised for both PG students and research supervisors. McCormack ${ }^{[18]}$ asserts that the difference between expected and perceived research supervision is the major contributing factor to the drop-out rate of PG students.

\section{Nature of support}

Respondents were generally satisfied with the support of their research supervisors. A large proportion (60\%) strongly agreed that their supervisors have the subject knowledge and skills to adequately support their research projects. Lessing and Schulze ${ }^{[10]}$ assert that many Master's degree students acknowledge the competence of their research supervisors. However, only $55 \%$ of the respondents strongly agreed that their supervisors provided guidance regarding the time frame for submitting their dissertations. This could be due to the workload and/or lack of expertise of research supervisors. However, the degree to which research supervisors take students' concerns seriously increases the students' trust in them. ${ }^{[19]}$ The results of this study show that fewer than half of the participants $(44.6 \%)$ believed that research supervisors understood respondents' difficulties.

It is noteworthy that almost half of the respondents (51.8\%) were highly satisfied with the guidance regarding topic selection and refinement. These results agree with those of Lessing and Schulze, ${ }^{[10]}$ who indicate that students are generally satisfied with the support they receive from research supervisors in terms of guidance in the choice of an appropriate framework. Some research supervisors are perceived as having little expertise with which to assist PG students during the conceptual phase of the research project. Consequently, it is pertinent to train research supervisors to provide good guidance in terms of this critical aspect of the research process.

\section{Designing and planning of the study}

The designing and planning phase follows and depends strongly on the conceptual phase. Winsett and Cashion ${ }^{[20]}$ assert that a research method is determined by research questions. Therefore, the research method for a study depends on the problem of the study, rather than the objective of the researchers. To successfully complete research therefore requires that students be guided by a supervisor who has an in-depth knowledge of the correct and relevant methodology. The findings of this study underscore the fact that fewer than half $(46.6 \%)$ of the respondents strongly agreed that they had received good guidance on research methodology from their research supervisors. In light of this finding, it is concluded that most research supervisors at the university where this study was conducted were not effective in providing good guidance on research methodology.

The outcome of the conceptual phase and the designing and planning phase is the actual research proposal. If students receive little or no guidance while creating their research proposal and obtain negative feedback from academics with reference to their proposal presentation, they become discouraged and demotivated with regard to the research process ${ }^{[21]}$ and may therefore disengage themselves from the study. This has a negative effect, which results in late completion of their degree, while some even abandon their studies.

The majority of respondents perceived guidance from research supervisors in the empirical and analytical phases of the research to be moderate. This demonstrates that research supervisors do act as facilitators, which could be a source of drive and motivation to continue with a research career.

More than half of the respondents (62.5\%) strongly agreed that they received helpful feedback on their progress, which is considered a source of motivation. This means that these respondents perceive their research supervisors as having the facilitation skills to encourage them to achieve their full potential. Research supervisors are perceived as sometimes providing delayed feedback. This could be due to the traditional face-toface model currently used in the selected school, while the majority of the respondents are part-time students with full-time jobs. Consequently, communication between students and supervisors is often delayed. It is noteworthy that there is a need for capacity building among research supervisors at PG level to enable them to adopt other than face-to-face methods, such as internet conferencing, wikis, Skype, and accommodating part-time students more effectively.

The period of research supervision and the time the student spends with his/her supervisor were also identified as factors that influence how PG students perceive their research supervisors. Spearman's Rho test of these variables produced an output of $-0.322(p=0.016)$, which indicates a negative correlation. This suggests that when students spend a longer time with their supervisors owing to the extended duration of the research period, familiarity may breed contempt and they may consider their supervisors to be less capable. Effective research supervisors are those who guide, mentor and assist the students to complete their degrees in the expected minimum time frames.

It emerged that there was a significant relationship between perceived research supervision and mode of attendance (part time and full time). The result of the Mann-Whitney $U$-test was $143.00(p=0.031)$. Full-time PG students were more satisfied with their research supervisors (mean rank 38.00) than part-time students (mean rank 26.18). This study underscores the traditional model of face-to-face supervision benefiting full-time students, but disadvantaging part-time students. ${ }^{[2,15]}$

The traditional model is often characterised by slow throughput rates, unacceptable behaviour by research supervisors, disputes between students and supervisors and a general lack of clarity regarding procedures and regulations for the supervision process. ${ }^{[15]}$ It is difficult for part-time students who are employed full time to meet with their research supervisors during working hours. Therefore, there is a need to incorporate an online research supervision model to accommodate part-time PG research students. Nonetheless, the implementation of such a model should be done carefully, as it requires expertise by research supervisors in both research and online facilitation skills. Furthermore, students participating in this manner require adequate computer skills; both students and research supervisors need to be sufficiently prepared for this model. To minimise isolation, research seminar strategies would need to be encouraged to support the model so that the practical implications of supervising research and receiving supervision can be managed.

Gender, age and marital status did not influence students' perceptions of research supervisors. Currently, HEIs accommodate all students without discrimination on the basis of age, gender and marital status. Given that adult students are very motivated to pursue their studies, they perform 
well because they are fully engaged with the research work. ${ }^{[22]}$ Previous qualifications do not influence the perceptions of research supervisors, as PG students are recruited based on specified standards as stipulated in the College of Health Sciences Handbook. ${ }^{[23]}$ There was also no difference in terms of current specialisation, possibly because PG students in this study were assigned to research supervisors by the school without considering their specialisation.

\section{Conclusion and recommendations}

The results of this study show that the majority of respondents acknowledged their supervisors as being adequately knowledgeable and skilled to support their research projects. However, many of the respondents only moderately agreed that their supervisors understood their difficulties. A high level of satisfaction was also found relating to guidance on topics. Most respondents displayed moderate satisfaction regarding the formulation of the purpose and objectives of their research. However, fewer than half strongly agreed that they had received good guidance from their research supervisors on research methodology. This implies that the majority of students perceived their research supervisors as being less skilled in research methodology. Overall, the majority of respondents were moderately satisfied with the support of their research supervisors.

The findings also revealed an inverse relationship between the duration of supervision and respondents' perceptions of the ability of research supervisors. Full-time PG students were more satisfied with their research supervisors than part-time students. This study emphasises how the traditional model of face-to-face supervision benefits full-time students, but disadvantages part-time students. The findings also indicate that there is no relationship between the perceptions of research supervisors and gender, age, marital status, previous qualification and current specialisation in nursing.

To improve the quality of research supervision, there is a need to include a research supervision module in the curriculum of nurse educators to build the capacity of research supervisors with regard to the entire research process. Furthermore, to explore the power of technology, it is necessary to adopt online research supervision to accommodate both part-time and full-time PG students.

\section{References}

1. Blass E, Jasman A, Shelley S. Postgraduate research students: You are the future of the academy. Futures 2012;44(2):166-173. DOI:10.1016/j.futures.2011.09.009

2. Zhao F. Transforming quality in research supervision: A knowledge-management approach. Quality Higher Educ 2003;9(2):187. DOI:10.1080/1353832032000104807

3. Severisson E. Research supervision: Supervisory style, research-related tasks, importance and quality, part 1. J Nurs Manag 2012;20(2):215-223. DOI:10.1111/j.1365-2834.2011.01361.x

4. Trudgett M. Western places, academic spaces and indigenous faces: Supervising indigenous Australian postgraduate students. Teach Higher Educ 2011;16(4):389-399. DOI:10.1080/07294360.2014.890576

5. Frenk J, Chen L, Bhutta ZA, et al. Health professionals for a new century: Transforming education to strengthen health systems in an interdependent world. Lancet 2010;376(9756):1923-1958. DOI:10.1016/S01406736(10)61854-5

6. South African Nursing Council. Regulations concerning the minimum requirements for registration of the additional qualification in nursing education, 2010. http://www.sanc.co.za/regulat/Reg-ned.htm (accessed 19 July 2016).

7. Tettey WJ. Challenges of Developing and Retaining the Next Generation of Academics: Deficits in Academic Staff Capacity at African Universities. Calgary: University of Calgary, 2010.

8. Millberg LG, Berg L, Lindström I, Petzäll K, Öhlén J. Tensions related to implementation of postgraduate degree projects in specialist nursing education. Nurse Educ Today 2011;31(3):283-288. DOI:10.1016/j.nedt.2010.11.012 9. Singh S. An intervention to assist students with writing their dissertations and theses. S Afr J Higher Educ 2011;25(5):1020-1030.

10. Lessing A, Schulze S. Postgraduate supervision: Students' and supervisors' perceptions. Acta Academica 2003;35(3):161-184. DOI:10.4314/sajhe.v16i2.2525

11. College of Health Sciences. College of Health Sciences Handbook. Durban: University of KwaZulu-Natal, 2013.

12. Hodsdon L, Buckley A. Postgraduate Research Experience Survey. York: Higher Education Academy, 2011.

13. Abdullah MNLY, Evans T. The relationships between postgraduate research students psychological attributes an their supervisors supervision training. Procedia Soc Behav Sci 2012;31:788-973. DOI:10.1016/j.sbspro.2011.12.142 14. Brink H, van der Walt C, van Rensburg G. Fundamentals of Research Methodology for Health Professionals Cape Town: Juta, 2006.

15. Council on Higher Education. Postgraduate Research and Supervision. Pretoria: CHE, 2007.

16. Ismail A, Abiddin NZ, Hassan A. Improving the development of postgraduates' research and supervision. Int Educ Studies 2011;4(1):78-89. DOI:10.5539/ies.v4nlp78

17. Department of Education. A New Funding Framework: How Government Grants are Allocated to Public Higher Education Institutions. Pretoria: DoE, 2004:1-20.

18. McCormack $C$. Tensions between student and institutional conceptions of postgraduate research. Studies Higher Educ 2004;29(3):319-334. DOI:10.1080/03075070410001682600

19. Segrott J, McIvor M, Green B. Challenges and strategies in developing nursing research capacity: A review of the literature. Int J Nurs Studies 2006;43(5):637-651. DOI:10.1016/j.ijnurstu.2005.07.01

20. Winsett RP, Cashion AK. The nursing research process. Nephrol Nurs J 2007;34(6):635-643.

21. Ssegawa JK, Rwelamila PD. The research skill factor as a cause for high postgraduate attrition rate. J Engineer Design Technol 2009;7(3):293-322. DOI:10.1108/17260530910998703.

22. Quinn FM, Hughes SJ. Quinn's Principles and Practice of Nurse Education. 5th ed. Delta Place: Nelson Thornes 2007.

3. College of Health Sciences. College of Health Sciences Handbook. Durban: University of KwaZulu-Natal, 2012 . 